\title{
Preduodenal Portal Vein: A Cause of Duodenal Obstruction in One Case and Incidental Finding in Another
}

Almoutaz A Eltayeb*

Pediatric surgery unit, Assiut university children hospital, Egypt

\begin{abstract}
Preduodenal portal vein is rare congenital anomaly that is usually associated with other gastrointestinal, cardiac, pancreatic and biliary anomalies. There are few case reports in the literature about this anomaly. Two cases of PDPV presented to Assiut university children hospital with manifestation of duodenal obstruction without being diagnosed either antenatal or preoperatively. Although rare; PDPV should always be suspected in all cases of duodenal obstruction.
\end{abstract}

Keywords: Duodenal obstruction; Preduodenal portal vein

\section{Background}

Preduodenal portal vein (PDPV) is rare congenital anomaly that was first described by knight in 1921 [1] and caused by anteriorly placed portal vein as a result of embryonic mal development. During early embryonic life the primitive gut is drained by two parallel vitelline veins. These two parallel veins are connected by three anastomotic branches: cephalic branch (within the liver), middle branch (posterior to the duodenum) and caudal one (anterior to the duodenum). Later on both the caudal and cephalic anastomotic branches with the caudal part of the right vitelline vein and the cephalic part of the left vitelline vein disappear, leaving an S shape portal vein behind the duodenum. If the middle and cephalic branches disappear together with the left vitelline vein PDPV arise [2,3] PDPV usually associated with malrotation, situs inversus viscerum, duodenal atresia, annular pancreas and biliary malformation [4]. There are few case reports in the literature about this anomaly. In this case report Two cases of PDPV presented to Assiut university children hospital during the last 8 years with manifestation of duodenal obstruction without being diagnosed either antenatal or preoperatively.

\section{Case Reports}

\section{Case 1}

Case 1 was a full term baby, weight 2,340 gm delivered by normal vaginal delivery. On the $2^{\text {nd }}$ day after delivery the baby developed persistent non bilious vomiting he was transferred to Assiut university children hospital at the age of 10 days with dehydration, poor general condition, poor reflexes and mild abdominal distension. His clinical examination did not revealed any clinical congenital anomalies. The plain $\mathrm{x}$ ray erect showed double bubble sign. Also the upper gastrografin study showed dilated stomach and first part of the duodenum with delayed passage of the dye further. On exploration both the stomach and $1^{\text {st }}$ part of duodenum were markedly dilated and the portal vein was abnormally crossing in front of the first part of the duodenum (Figure 1). Malrotation of the gut was also noted. After mobilization of the duodenum and the Ladd's band was excised the second part of the duodenum which was collapsed became distended. Ladd's procedure is followed by duodenotomy to exclude any intra luminal duodenal pathology. Then side to side duodenoduodenostomy in front of the portal vein was done. The baby started oral feeding on the $3^{\text {rd }}$ post operative day with uneventful early post operative period and was discharged on the $8^{\text {th }}$ post operative day.

\section{Case 2}

Case 2 was a 2 months old male presented by persistent non bilious vomiting. The patient referred to our unit with dehydration and hypochloraemic metabolic alkalosis. After resuscitation and correction of the electrolyte disturbance the preoperative plain and contrast study prove that the patient has situs inversus totalis with markedly dilated stomach and first part of duodenum with delayed passage of the dye further (Figure 2). No other congenital anomalies could be detected. On exploration both the stomach and the first part of duodenum were markedly dilated. The rest of the duodenum was collapsed, kinked, none rotated and compressed by abnormally positioned anterior portal vein which was crossing in front of the first part of the duodenum (Figure 3). Duodenotomy to exclude any intra luminal duodenal pathology was done followed by side to side duodenoduodenostomy in front of the PDPV was amenable after mobilization and straightening of the duodenum. The patient started oral feeding on the $4^{\text {th }}$ post operative day with uneventful post operative course and was discharged on the $9^{\text {th }}$ post operative day. Both cases did not show any post operative

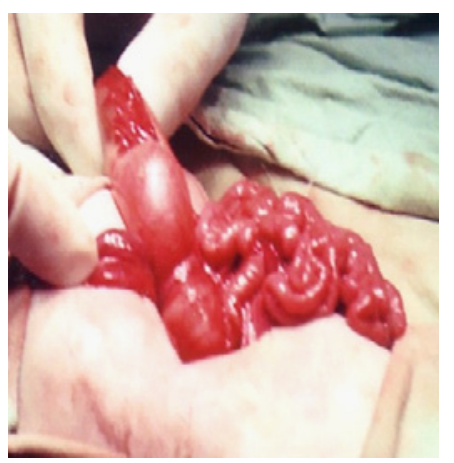

Figure 1: Dilatation of the stomach and first part of duodenum; the portal vein abnormally crossing in front of the duodenum.

*Corresponding author: Almoutaz A Eltayeb MD, Pediatric surgery unit, Assiut university children hospital, Egypt, Tel: 00201221657863; E-mail: almoutazeltayeb@hotmail.com

Received December 04, 2011; Accepted January 31, 2012; Published February 06, 2012

Citation: Atahan K, Çökmez A, Durak E, Tarcan E (2012) Fistulojejunostomy in the Management of Chronic External Biliary Fistula. Surgery 2:109. doi:10.4172/21611076.1000109

Copyright: (C) 2012 Atahan K, et al. This is an open-access article distributed under the terms of the Creative Commons Attribution License, which permits unrestricted use, distribution, and reproduction in any medium, provided the original author and source are credited. 


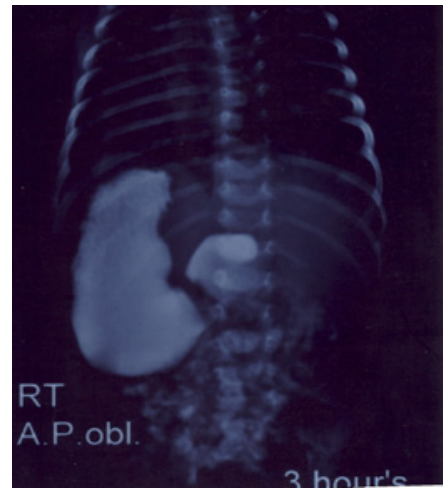

Figure 2: Situs inversus with dilated stomach and first part of duodenum and delayed passage of the dye to the small intestine.

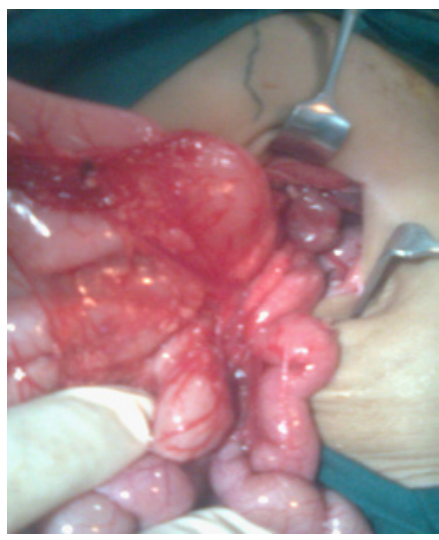

Figure 3: PDPV and Situs inversus with kinking and obstruction of the non rotated duodenum.

complications or recurrence of symptoms during their follow up period which was 9 months for the first case and 1 year for the second.

\section{Discussion}

Since its first description [1] less than 100 patients of PDPV has been reported in the literature [5]. PDPV usually associated with other anomalies such as; duodenal, cardiac, biliary, pancreatic and splenic anomalies [2,3,6]. Yi et al [7] reviewed the largest series of PDPV cases yet. He reported 323 cases of PDPV with multiple associated anomalies including; intestinal malrotation in $64 \%$, situs inversus in $26 \%$, duodenal and pancreatic anomalies in $26 \%$ \& $22 \%$ of them. Prenatal diagnosis or preoperative identification of PDPV as a cause of duodenal obstruction is rarely made even in the cases of duodenal obstruction caused by the PDPV [4]. Both our cases have not been diagnosed either prenatally or preoperatively and were incidentally found during operation. As $50 \%$ of cases of PDPV are a symptomatic discovered incidentally during surgery; this incidental finding should alert the surgeon to be familiar to deal with it to prevent unnecessary trauma during cholecystectomy, gastrectomy and pancreatectomy with serious outcomes [2]. Although duodenal obstruction has been noted to be the most common clinical presentation in the remaining $50 \%$ of cases only in few of them the obstruction was clearly caused by PDPV itself $[8,9]$. Esscher [9] reviewed 54 cases of PDPV; two of them the duodenal obstruction was related to the PDPV itself. In the majority of cases the obstruction was caused by associated anomalies such as duodenal web, annular pancreas and intestinal Mal rotation or Non rotation [2]. In this case report Mal rotation in the first case was the cause of duodenal obstruction while both PDPV and non rotation in the second case was the cause of duodenal obstruction. Thus it is important to exclude any intrinsic or extrinsic cause of duodenal obstruction before refereeing the obstruction to the PDPV as a primary cause [6]. The preferred treatment of duodenal obstruction caused by PDPV is to bypass the obstruction either by duodeno-duodenostomy or gastro-duodenostomy [2]. In this case report both cases had duodenoduodenostomy and their post operative period was uneventfull.

\section{Conclusion}

Although rare; PDPV should always be suspected in all cases of duodenal obstruction. However other more common causes of duodenal obstruction should be looked for carefully to avoid non optimal procedure. Early intervention is important to avoid progressive deterioration of the patient especially if the patient came with persistent vomiting.

\section{References}

1. Knight $\mathrm{HO}$ (1921) An anomalous portal vein with its surgical dangers. Ann Surg 74: 697-699.

2. Mordehai J, Cohen Z, Kurzbart E, Mares AJ (2002) Preduodenal porta vein causing duodenal obstruction associated with situs inversus, intestinal malrotation and polysplenia: A case report. J Pediatr Surg 37: E5.

3. Shah OJ, Robbani I, Khuroo MS (2009) Preduodenal portal vein with preduodenal bile duct: an extremely rare anomaly. Am J Surg 197: E43-E45.

4. Choi SO, Taegu PWH (1995) Preduodenal portal vein: A cause of prenatally diagnosed duodenal obstruction. J Pediatr Surg 30: 1521-1522.

5. Baglaj M, Gerus S (2012) Preduodenal portal vein, malrotation and high jejuna atresia: a case report. J Pediatr Surg 47: E27-E30

6. Singal AK, Ramu C, Paul S, Matthai J (2009) Preduodenal portal vein in association with midgut malrotation and duodenal web- triple anomaly? J Pediatr Surg 44: E5-E7.

7. Yi SQ, Tanaka S, Tanaka A, Shimokawa T, RU F, et al. (2004) An extremely rare inversion of the preduodenal portal vein and common bile duct associated with multiple malformations Report of an adult cadaver case with abrief review of the literature. Anat Emberyol 208: 87-96.

8. Fernandes ET, Burton EM, Hixson SD, Hollabaugh RS (1990) Preduodena portal vein: Surgery and radiographic appearance. J Pediatr Surg 25: 1270 1272.

9. Esscher T (1980) Preduodenal portal vein: A case of intestinal obstruction? J Pediatr Surg 15: 609-612. 